\title{
The Relationship between Microscopic Lesions and Different Types of Clostridium perfringens and their Related Toxins by Sandwich ELISA in Cattle
}

\author{
Farhang Sasani ${ }^{1 *}$, Havva Marzban ${ }^{2}$, Javad Javanbakht ${ }^{1}$, Farhad Moosakhani ${ }^{3}$ and Mahsa Imanparast ${ }^{3}$ \\ ${ }^{1}$ Faculty of Veterinary Medicine, Department of Pathology, Tehran University, Tehran, Iran \\ ${ }^{2}$ Faculty of Veterinary Medicine, Tehran University, Tehran, Iran \\ ${ }^{3}$ Faculty of Veterinary Medicine, Department of Microbiology Sciences, Islamic Azad University, Branch of Karaj, Karaj, Iran
}

\begin{abstract}
Obviously, one of the most important causes of Enterotoxaemia in domestic animals is Clostridium perfringens. In present study, C. perfringens type A $(56.66 \%)$, type $D(26.66 \%)$ and type $B(16.66 \%)$ were respectively the most abundant bacteria in intestinal samples of 30 cattle and calves with enterotoxaemia. The incidence of $\alpha, \beta$ and $\varepsilon$ toxins in extracted intestinal contents, by Sandwich ELISA method, were determined $89 / 98 \%, 99 / 19 \%$ and $33.33 \%$ respectively. Histopathologic examination of different organs from 12 cattle and calves with enterotoxaemia and C.perfringens affection indicated following lesions; Heart: congestion (40\%), hemorrhage (30\%), mild myolysis $(10 \%)$, sarcocystosis $(30 \%)$, lymphocytic endocarditis $(10 \%)$, pericarditis $(10 \%)$ and myocardiocyte hypertrophy $(20 \%)$. Liver: hepatitis $(27 \%)$, coagulative necrosis $(36 \%)$, hemorrhage $(19 \%)$, severe hepatic fibrosis $(9 \%)$ and hepatic abscess $(9 \%)$. Spleen: congestion (33\%), hemorrhage $(33 \%)$, lymphoid tissue depletion $(16 \%)$, capsular fibrinohemorrahgic Inflammation (16\%) and hemosidrosis (33\%). Intestine: necrohemorrahgic enteritis $(40 \%)$, lymphoplasmocytic enteritis $(50 \%)$, necrotic and suppurative subserosal Inflammation $(10 \%)$, congestion $(10 \%)$, edema $(10 \%)$ and shortening and fusion of Villi $(10 \%)$. Lymph nodes: congestion $(25 \%)$, thrombosis and hemorrhage $(25 \%)$, edema $(25 \%)$, lymphocytolysis $(25 \%)$ and fibrinous lymphadenitis $(25 \%)$. Lung: congestion $(36 \%)$, hemorrhage $(9 \%)$, edema $(27 \%)$, atelectasis $(9 \%)$, emphysema $(9 \%)$, embolic pneumonia (9\%), purulent bronchopneumonia (18\%), fibrinous pneumonia (45\%), cuffing pneumonia (18\%), Interlobular fibrosis $(9 \%)$ and pulmonary abscess $(9 \%)$. Kidney: congestion $(12.5 \%)$, acute tubular necrosis $(25 \%)$, glomerular atrophy $(12.5 \%)$, interstitial nephritis $(50 \%)$ and hyaline droplets $(12.5 \%)$. The present data demonstrate that in the laboratory setting the reproducibility, sensitivity and linear dose response of ELISA allows quantitative estimation of different types of bacteria and respective toxins activity. This could be useful for monitoring toxin production. Our study suggested that although some of the lesions were triggered by $C$. perfringens, some may be caused by other pathogens which were not investigated in this research.
\end{abstract}

Keywords: Clostridium perfringens; Histopathology; ELISA; Organs; Bacteriology

\section{Introduction}

Clostridium perfringens, anaerobic gram positive bacillus, is an important factor of clostridial enteritis in domestic animals [1-5]. Furthermore, at least 17 exotoxins are produced by this bacterium among which 4 of them possess essential role in pathogenesis of clostridial diseases. This bacterium is divided into 5 pathogenic types according to the 4 types of exotoxins (Alpha ( $\alpha$ ), Beta ( $\beta$ ), Epsilon $(\varepsilon)$, Iota (I)) that are different from clinical point of view according to the type of produced toxins, type of bacteria and also relevant factors of host and environment conditions. In addition, the common manifestations are enteritis, diarrhea, neural signs and accidental death. Thus, this organism causes losses, reduction of growth and large economic damages to ranchers and animal industry [1-6].

Apparently, this bacterium is natural flora of human being and animal bowel; hence recognition of bacteria is not only sufficient. Therefore, determination of exotoxin type and its amount is necessary. The aim of this study was to investigate relationship between histopathology of various organs and different types of $C$. perfringens bacteria and recognition of relevant exotoxins by Sandwich ELISA method in tissue samples of affected cattle and sheep in addition to determination amount of C. perfringens bacteria in microbiologic bowel samples.

\section{Materials and Methods}

In present study, the histopathological examination of 30 diagnostic C. perfringens out of referring samples to veterinary laboratory was carried out in addition to the microbiology diagnostic tests including determination of type of bacteria, type of exotoxin by Sandwich ELISA method, samples of different organs of 12 sick calves and cow cattle which were positive from C. perfringens. In the Sandwich ELISA method, sensitive 96-cell polite has been used by specialized monoclonal antibody for $\alpha, \beta$ and $\varepsilon$ exotoxins using special kits of Bio-X diagnostics company. The tests have been carried out according to the kit instruction [7-9].

*Corresponding author: Farhang Sasani, Faculty of Veterinary Medicine Department of Pathology, Tehran University, Tehran, Iran, E-mail: fsasani@ut.ac.ir

Received January 30, 2013; Accepted February 25, 2013; Published February 28, 2013

Citation: Sasani F, Marzban H, Javanbakht J, Moosakhani F, Imanparast M (2013) The Relationship between Microscopic Lesions and Different Types of Clostridium perfringens and their Related Toxins by Sandwich ELISA in Cattle. J Microb Biochem Technol 5: 034-038. doi:10.4172/1948-5948.1000096

Copyright: () 2013 Sasani $F$, et al. This is an open-access article distributed under the terms of the Creative Commons Attribution License, which permits unrestricted use, distribution, and reproduction in any medium, provided the original author and source are credited 
Citation: Sasani F, Marzban H, Javanbakht J, Moosakhani F, Imanparast M (2013) The Relationship between Microscopic Lesions and Different Types of Clostridium perfringens and their Related Toxins by Sandwich ELISA in Cattle. J Microb Biochem Technol 5: 034-038. doi:10.4172/19485948.1000096

\section{Histopathologic examination}

Tissue specimens including heart, liver, spleen, bowel, lymph node, lung and kidney of each animal were taken $(1 \times 1 \times 0.5 \mathrm{~cm})$ and located in neutral formalin $10 \%$ for a period of $24-48$ hours. Following molding, the samples were put in paraffin and prepared of samples with 5 micron thickness by microtome and stained by $\mathrm{H} \&$ E method.

\section{Results}

\section{Microbiological findings}

In this study, bacteriological tests were applied on 30 cattle samples suspected to $C$. perfringens affection and indicated frequency of contamination with $C$. perfringens type A-56.66\%, type B-16.66\% and type D-26.66\%; however, no contamination by type C was observed. By means of Sandwich ELISA method, presence of $\alpha, \beta$ and $\varepsilon$ toxins related to this bacterium in the refined intestinal contents was determined equal to $89.98 \%, 19.99 \%, 33.33 \%$, respectively (Table 1 ).

\section{Histopathological findings}

In this examination, the tissue samples (heart, liver, intestine, lymph node, lung and kidney) of 12 affected cattle and calves with $C$. perfringens infection have been investigated histopathologically, out of which 10,1 and 1cases were related to type A, type B and type D respectively. The results have been depicted respectively in tables 1, 5 and 6.
Heart: Sarcocystosis 30\% (3 cases), lymphocytic endocarditis 10\% (1 case), pericarditis 10\% (1 case) and myocardiocytic hypertrophy have been observed $20 \%$ ( 2 cases) in addition to following lesions (Table 2).

Liver: Severe hepatic fibrosis 9\% (1 case), hepatic abscesses 9\% (1 case) and fatty liver have been observed $36 \%$ ( 4 cases) in addition to following lesions (Table 3).

Spleen: In addition to the following complications in the histopathological examinations, another complication such as hemosiderosis was observed 33\% ( 2 cases) (Table 4 ).

Lung: In addition to the following complications, in histopathological examination, symbolic pneumonia 9\% (1 case), suppurative bronchopneumonia $9 \%$ (1 case), interstitial pneumonia $45 \%$ ( 5 cases), cuffing pneumonia 18\% ( 2 cases), interlobular fibrosis 9\% ( 1 case) and abscess 9\% (1 case) have been observed (Table 7).

Kidney: In addition to the following complications, interstitial nephritis 50\% (4 cases) and hyaline droplets have been observed around $12.5 \%$ ( 1 case) as well (Table 1$)$.

\section{Discussion}

According to the results, the most common type in the reference samples which developed tissue lesions was type A. In references, C. perfringens type $\mathrm{A}$ is mentioned as the most prevalent type in mammals, avian and environment $[5,10]$. Many researchers have

\begin{tabular}{|c|c|c|c|c|c|c|}
\hline \multirow{3}{*}{$\begin{array}{l}\text { Number/type of } \\
\text { bacterium }\end{array}$} & \multicolumn{6}{|c|}{ Toxin } \\
\hline & \multicolumn{2}{|c|}{$\varepsilon$} & \multicolumn{2}{|c|}{$\beta$} & \multicolumn{2}{|c|}{$\alpha$} \\
\hline & $\mathrm{P}$ & $\mathrm{N}$ & $\mathrm{P}$ & $\mathrm{N}$ & $P$ & $\mathrm{~N}$ \\
\hline $\mathrm{A} / 17$ & 0 & 0 & 0 & 0 & $100 \%$ & 17 \\
\hline $\mathrm{B} / 5$ & $40 \%$ & 2 & $100 \%$ & 5 & $60 \%$ & 3 \\
\hline $\mathrm{D} / 8$ & $100 \%$ & 8 & $12.5 \%$ & 1 & $87.5 \%$ & 7 \\
\hline Total & $33.33 \%$ & 10 & $19.99 \%$ & 6 & $89.98 \%$ & 27 \\
\hline
\end{tabular}

Table 1: The rate of different Clostridium perfringens toxins by Sandwich ELISA method in the samples referred to veterinary diagnostic labs.

\begin{tabular}{|c|c|c|c|c|c|c|c|c|}
\hline \multirow[b]{2}{*}{ lesions } & \multirow[b]{2}{*}{$\mathrm{N}$} & \multirow[b]{2}{*}{$\mathrm{P}$} & \multicolumn{3}{|c|}{ Toxin } & \multicolumn{3}{|c|}{ Type of bacterium } \\
\hline & & & $\varepsilon$ & $\beta$ & $\alpha$ & $\mathrm{D}$ & B & A \\
\hline Hyperemia & 4 & $40 \%$ & 0 & $25 \%$ & $100 \%$ & 0 & $25 \%$ (1case) & $75 \%$ (3cases) \\
\hline Hemorrhage & 3 & $30 \%$ & $33.33 \%$ & 0 & $100 \%$ & $33.33 \%$ (1case) & 0 & $66.66 \%$ (2cases) \\
\hline Mild myolysis & 1 & $10 \%$ & 0 & 0 & $100 \%$ & 0 & 0 & $100 \%$ \\
\hline
\end{tabular}

Table 2: The role of different types of Clostridium perfringens toxins in each one of cardiac complications.

\begin{tabular}{|c|c|c|c|c|c|c|c|c|}
\hline \multirow[b]{2}{*}{ Lesions } & \multirow[b]{2}{*}{$\mathrm{N}$} & \multirow[b]{2}{*}{$P$} & \multicolumn{3}{|c|}{ Toxin } & \multicolumn{3}{|c|}{ Type of bacterium } \\
\hline & & & $\varepsilon$ & $\beta$ & $\alpha$ & $\mathrm{D}$ & B & A \\
\hline Hepatitis & 3 & $27 \%$ & $33.33 \%$ & $33.33 \%$ & $100 \%$ & $\begin{array}{l}33.33 \% \\
(1 \text { case })\end{array}$ & $\begin{array}{l}33.33 \% \\
(1 \text { case })\end{array}$ & $33.33 \%$ (1case) \\
\hline $\begin{array}{c}\text { Coagulative } \\
\text { necrosis }\end{array}$ & 4 & $36 \%$ & $25 \%$ & $25 \%$ & $100 \%$ & $\begin{array}{c}25 \% \\
(1 \text { case) }\end{array}$ & $\begin{array}{c}25 \% \\
(1 \text { case) }\end{array}$ & $50 \%$ ( 2 cases) \\
\hline Mild myolysis & 2 & $19 \%$ & 0 & 0 & $100 \%$ & 0 & 0 & $100 \%$ (2cases) \\
\hline
\end{tabular}

Table 3: The effect of different types of Clostridium perfringens toxins on each one of hepatic complications.

\begin{tabular}{|c|c|c|c|c|c|c|c|c|}
\hline \multirow[b]{2}{*}{ Lesions } & \multirow[b]{2}{*}{$\mathrm{N}$} & \multirow[b]{2}{*}{$\mathrm{P}$} & \multicolumn{3}{|c|}{ Toxin } & \multicolumn{3}{|c|}{ Type of bacterium } \\
\hline & & & $\varepsilon$ & $\beta$ & $\alpha$ & $\mathrm{D}$ & B & A \\
\hline Hyperemia & 2 & $33 \%$ & 0 & 0 & $100 \%$ & 0 & 0 & $100 \%$ (2cases) \\
\hline Hemorrhage & 2 & $33 \%$ & 0 & 0 & $100 \%$ & 0 & 0 & $100 \%$ (2cases) \\
\hline Lymphoid tissue depletion & 1 & $16 \%$ & 0 & 0 & $100 \%$ & 0 & 0 & $100 \%$ (1case) \\
\hline Capsular fibrino-hemorrhagic presplenitis & 1 & $16 \%$ & 0 & 0 & $100 \%$ & 0 & 0 & $100 \%$ (1 case) \\
\hline
\end{tabular}

Table 4: The share of different types of Clostridium perfringens toxins in producing each one of splenic complications. 
Citation: Sasani F, Marzban H, Javanbakht J, Moosakhani F, Imanparast M (2013) The Relationship between Microscopic Lesions and Different Types of Clostridium perfringens and their Related Toxins by Sandwich ELISA in Cattle. J Microb Biochem Technol 5: 034-038. doi:10.4172/19485948.1000096

recognized C. perfringens type A with higher prevalence in comparison with other types of this bacterium in mammals and birds [4,11-14] (Table 8). Diseases resulting from C. perfringens in diverse organs indicate several histopathological lesions $[5,10]$. In current study, 4 cases revealed hyperemia in heart tissues, 3 cases of which were related to C. perfringens type A and one case was related to type B. In sample of type A hemorrhage, acute pericarditis, mild myocardiocyte hypertrophy, sarcocystosis, lymphocytic endocarditis and mild myolysis with bacterial colonies were observed. Ghareib and Amer [15] demonstrated histopathological changes in laboratory animals' heart, with type A such as vascular congestion, edema, and degenerative changes in myocardium and congestion only in cases with type D.

C. perfringens type $\mathrm{D}$ produce toxin known as an angiotoxin that causes pericardial effusions in heart [5]. Investigations on type $\mathrm{D}$ in calves ascertained heart lesions including hydropericardium, protein-rich fluid, myocardial hemorrhage, endocardial petechiae and subendocardial hemorrhage around mitral valves [3,16-18]. In present study, one case of infection resulting from type $\mathrm{D}$ and one case related to type $\mathrm{B}$, focal coagulation necrosis and hepatitis were observed as well as bacterial colonies in infection arising from type $\mathrm{D}$ in some parts of liver. Ghareib and Amer [15] in guinea pigs demonstrated vacuoles degeneration, granular hepatocytes and leukocyte infiltration in portal areas with type $\mathrm{D}$ and in that group with type $\mathrm{A}$, they observed hepatitis and congestion in central and portal veins, intravascular hemolysis, necrosis, vacuoles degeneration of hepatocytes and proliferation of kupffer cells. In this study, the lesions caused by type A including fatty liver, hemorrhage, acute hepatic necrosis and fibrosis and in one case, hepatic abscess and bacterial colonies were observed. Also four cases of fatty liver may have been resulted from hunger due to infections or anorexia. C. perfringens in spleen developed congestive splenomegaly [5]. In this study, we only separated C. perfringens type A from spleen and observed histopathological lesions as hyperemia, hemorrhage, hemosidrosis, lymphatic depletion and capsular fibrinohemorrhagic inflammation. In enterotoxaemia caused by type D in calf also, spleen

\begin{tabular}{|c|c|c|c|c|c|c|c|c|}
\hline \multirow[b]{2}{*}{ Lesions } & \multirow[b]{2}{*}{$\mathrm{N}$} & \multirow[b]{2}{*}{$\mathrm{P}$} & \multicolumn{3}{|c|}{ Toxin } & \multicolumn{3}{|c|}{ Type of bacterium } \\
\hline & & & $\varepsilon$ & $\beta$ & $\alpha$ & $\mathrm{D}$ & B & $\mathrm{A}$ \\
\hline Necrohemorrhagic enteritis & 4 & $40 \%$ & $25 \%$ & 0 & $100 \%$ & $\begin{array}{c}25 \% \\
(1 \text { case) }\end{array}$ & 0 & $75 \%$ (4cases) \\
\hline Lymphoplasmacytic enteritis & 5 & $50 \%$ & 0 & $20 \%$ & $100 \%$ & 0 & $20 \%$ & $80 \%$ (4cases) \\
\hline Diffuse necrotic \& purulent subserosal inflammation & 1 & $10 \%$ & 0 & 0 & $100 \%$ & 0 & 0 & $100 \%$ ( 1 case $)$ \\
\hline Hyperemia & 1 & $10 \%$ & 0 & 0 & $100 \%$ & 0 & 0 & $100 \%$ (1case) \\
\hline Edema & 1 & $10 \%$ & 0 & 0 & $100 \%$ & 0 & 0 & $100 \%$ (1case) \\
\hline Shortness and fusion of villi & 1 & $10 \%$ & 0 & 0 & $100 \%$ & 0 & 0 & $100 \%$ (1case) \\
\hline
\end{tabular}

Table 5: The role of different types of Clostridium perfringens toxins in producing each intestinal complication.

\begin{tabular}{|c|c|c|c|c|c|c|c|c|}
\hline \multirow[b]{2}{*}{ Lesions } & \multirow[b]{2}{*}{$\mathrm{N}$} & \multirow[b]{2}{*}{$\mathrm{P}$} & \multicolumn{3}{|c|}{ Toxin } & \multicolumn{3}{|c|}{ Type of bacterium } \\
\hline & & & $\varepsilon$ & $\beta$ & $\alpha$ & $\mathrm{D}$ & $\mathrm{B}$ & A \\
\hline Hyperemia & 1 & $25 \%$ & 0 & 0 & $100 \%$ & 0 & 0 & $100 \%$ \\
\hline Hemorrhage \& thrombosis & 1 & $25 \%$ & 0 & 0 & $100 \%$ & 0 & 0 & $100 \%$ \\
\hline Edema & 1 & $25 \%$ & 0 & 0 & $100 \%$ & 0 & 0 & $100 \%$ \\
\hline Lymphocytolysis & 1 & $25 \%$ & 0 & 0 & $100 \%$ & 0 & 0 & $100 \%$ \\
\hline Fibrinous lymphadenitis & 1 & $25 \%$ & 0 & 0 & $100 \%$ & 0 & 0 & $100 \%$ \\
\hline
\end{tabular}

Table 6: The share of different types of Clostridium perfringens toxins in producing each one of lymph node complications.

\begin{tabular}{|c|c|c|c|c|c|c|c|c|}
\hline \multirow[b]{2}{*}{ Lesions } & \multirow[b]{2}{*}{$\mathrm{N}$} & \multirow[b]{2}{*}{$P$} & \multicolumn{3}{|c|}{ Toxin } & \multicolumn{3}{|c|}{ Type of bacterium } \\
\hline & & & $\varepsilon$ & $\beta$ & $\alpha$ & $\mathrm{D}$ & B & A \\
\hline Hyperemia & 4 & $36 \%$ & $25 \%$ & $25 \%$ & $100 \%$ & $\begin{array}{c}25 \%(1 \\
\text { case) }\end{array}$ & $\begin{array}{c}25 \%(1 \\
\text { case) }\end{array}$ & $50 \%$ (2 cases) \\
\hline Hemorrhage & 1 & $9 \%$ & 0 & 0 & $100 \%$ & 0 & 0 & $100 \%$ \\
\hline Edema & 3 & $27 \%$ & $33.33 \%$ & 0 & $100 \%$ & $\begin{array}{c}33.33 \% \\
(1 \text { case })\end{array}$ & 0 & $66.66 \%$ ( 2 cases) \\
\hline Atelectasis & 1 & $9 \%$ & 0 & 0 & $100 \%$ & 0 & 0 & $100 \%$ (1case) \\
\hline Emphysema & 1 & $9 \%$ & 0 & 0 & $100 \%$ & 0 & 0 & $100 \%$ (1case) \\
\hline
\end{tabular}

Table 7: The share of different types of Clostridium perfringens toxins in producing each one of pulmonary complications.

\begin{tabular}{|c|c|c|c|c|c|c|c|c|}
\hline \multirow[b]{2}{*}{ Lesions } & \multirow[b]{2}{*}{$\mathrm{N}$} & \multirow[b]{2}{*}{$\mathrm{P}$} & \multicolumn{3}{|c|}{ Toxin } & \multicolumn{3}{|c|}{ Type of bacterium } \\
\hline & & & $\varepsilon$ & $\beta$ & $\alpha$ & $\mathrm{D}$ & $\mathrm{B}$ & A \\
\hline Hyperemia & 1 & $12.5 \%$ & 0 & 0 & $100 \%$ & 0 & 0 & $100 \%$ \\
\hline Acute tubular necrosis & 2 & $25 \%$ & $50 \%$ & 0 & $100 \%$ & $\begin{array}{c}50 \% \\
\text { (1case) }\end{array}$ & 0 & $50 \%$ (1case) \\
\hline Glomerular atrophy & 1 & $12.5 \%$ & 0 & 0 & $100 \%$ & 0 & 0 & $100 \%$ \\
\hline
\end{tabular}

Table 8: The share of different types of Clostridium perfringens toxins in producing each one of renal complications. 
Citation: Sasani F, Marzban H, Javanbakht J, Moosakhani F, Imanparast M (2013) The Relationship between Microscopic Lesions and Different Types of Clostridium perfringens and their Related Toxins by Sandwich ELISA in Cattle. J Microb Biochem Technol 5: 034-038. doi:10.4172/19485948.1000096

lesions were observed as splenitis, sub capsular congestion, hemorrhage and reticular tissue disorder [10].

Ghareib and Amer [15] indicated lymphatic follicles decrease and hemosiderosis of spleen in guinea pigs with type A and in those with type D, the splenic lymphatic follicles decrease was solely found [15]

Lulov et al. [19] reported mild hemosidrosis in enterotoxaemia caused by C.perfringens type $\mathrm{A}$ in calf. In this study, in cases with $C$. perfringens type A infection, intestinal lesions such as lymphoplasmocytic enteritis with shortening and fusion of villi and hemorrhagic enteritis may be caused by concurrent infections with other agents such as rotavirus or coronavirus [20].

Songer et al. [14] demonstrated the infections resulting from C. perfringens type A in calf, observed intestinal lesions including fatal hemorrhagic enteritis particularly at proximal duodenum with gram-positive bacteria, necrohemorrhagic inflammation of mucous membrane and emphysema.

Denison et al. [17] showed that 17 out of 20 cattle feces samples with hemorrhagic enteritis, $C$. perfringens type A was isolated and in histopathological examinations, they found severe focal submucosal hemorrhage with edema in small intestine. The results raised the relationship between presence of $C$. perfringens type $A$ and hemorrhagic bowel syndrome (HBS).

In current study, 3 cases of necrohemorrhagic lesions were observed and since we have obtained $C$. perfringens type A from these lesions, it is likely that HBS is important in these 3 cases. In Khorasan Razavi province, 2 dairy cattle with this syndrome were diagnosed and a large amount of $C$. perfringens was obtained from the culture of cattle bowel contents [1]. In present study, one case with $C$. perfringens type D manifested intestinal lesions as acute hemorrhagic enteritis with gas bubbles.

Ghareib and Amer [15] in guinea pigs with type A observed intestinal congestion, necrosis and degenerative changes of villi epithelial cells and proliferation of goblet cells and severe leukocyte infiltration and in those with type $\mathrm{D}$, intestinal hemorrhage and Pyre plaques decrease, edema and leukocyte infiltration in thick layer of mucus were observed. Additionally, in this study, intestinal lesions in one case with type B developed severe and diffuse lymphoplasmocytic enteritis. Uzal et al. (2010) [2] demonstrated intestinal lesions of type B mainly in small intestine. However, cecum and large spiral intestine were sometimes engaged. The lesions may be restricted to large intestine. Bloody contents of intestine with fibrin at aerosol surface of the intestine and adhesion are seen. In histopathological investigations, mesenteric hyperemia and focal or diffuse necrotic enteritis and intestinal emphysema can be observed. The luminal surface of intestine is covered by pseudomembrane composed of necrotic and degenerated cells and cell debris, inflammatory cells, fibrin, and large, thick bacilli with terminal spores.

In present study, lesions of lymph nodes included hyperemia, hemorrhage and thrombosis, edema, lymphocytolysis and fibrinous lymphadenitis. However, only C. perfringens type A was obtained out of them.

Uzal et al. (2010) [2] and Tajik et al. [21] reported lesions of lymph nodes as hyperemia and enlargement of mesenteric lymph nodes.

In this study, one case of $C$. perfringens type $\mathrm{D}$ with acute pulmonary hyperemia and edema with bacterial colonies were observed.
Pulmonary lesions reported in current study are consistent with the findings of other studies [1,21-23]. Furthermore, in pulmonary tissues with $C$. perfringens type $\mathrm{A}$, interstitial pneumonia, purulent fibrinous bronchopneumonia, abscess, interlobular fibrosis, edema, hyperemia, atelectasis, emphysema and bacterial colonies were observed which were correspondent to other researchers' findings [3,11,24,25]. In this study, 5 cases of interstitial pneumonia could be attributed to probable presence of other pathogenic agents like viruses and mycoplasma causing chronic pneumonia.

In case of kidney tissue, in this study one case of severe hyperemia and 4 cases of multifocal lymphoplasmocytic interstitial nephritis was found. Although lymphoplasmocytic interstitial nephritis is not much related to diseases caused by $C$. perfringens bacteria, this lesion may appear in disease such as leptospirosis, theileriosis, and malignant catarrhal fever (MCF).

In current study, acute tubular necrosis in one case of infection caused by C. perfringens type $\mathrm{D}$ and one case of type A were reported.

Hormitzky and Glastunbury [26] indicated early autolysis of kidneys, hemorrhage, subcapsular and renal cortex hyperemia in cattle following enterotoxaemia.

In a study on 36 cattle kidneys with $C$. perfringens, Ghareib and Amer [15] found hyperemia and vascular hypotrophy, degeneration and necrosis in loop of henle, capsule thickness and hemorrhage and leukocyte infiltration in kidneys with type A and glomerular atrophy, tubular necrosis and degeneration, hyperemia and edema with type D [15].

\section{Conclusion}

The present data demonstrate that in the laboratory setting the reproducibility, sensitivity and linear dose response of ELISA allows quantitative estimation of different types of bacteria and respective toxins activity. This could be useful for monitoring toxin production. We hope to take more effective actions to diagnose, control and prevent from these diseases by discovering the relationship between lesions and different types of bacteria and respective toxins. Further work is being undertaken to determine the predictive value of the tests in commercial cattle.

\section{References}

1. Uzal FA, Kelly WR, Morris WE, Assis RA (2002) Effects of intravenous injection of Clostridium perfringens type D epsilon toxin in calves. J Comp Pathol 126 71-75.

2. Uzal FA, Vidal JE, McClane BA, Gurjar AA (2010) Clostridium perfringens Toxins Involved in Mammalian Veterinary Diseases. The Open Toxinology Journal 3: 24-42

3. Songer JG (1996) Clostridial enteric diseases of domestic animals. Clin Microbiol Rev 9: 216-234.

4. Niilo L, Avery RJ (1963) Bovine "Enterotoxemia" I. Clostridium perfringens Types Isolated from Animal Sources in Alberta and Saskatchewan. Can Vet J 4: 31-36.

5. Howard BG (2007) Alimentary system. In: Pathologic basis of veterinary medicine, McGavin MD, Zachary JF, (ed.). (4thedn), Mosby Elsevier, USA 301 391.

6. Radostitis OM, Gay CC, HinchcliffK W, Constable PD (2007) Veterinary medicine: A textbook of the diseases of cattle, horses, sheep, pigs and goats. (10thedn), Saunders 836-843.

7. Joshy L, Chaudhry R, Dhawan B, Das BK, Kumar L, et al. (2006) Enterotoxigenic Clostridium perfringens and sporadic diarrhoea: a study from an Indian tertiary care hospital. J Med Microbiol 55: 1757-1758. 
Citation: Sasani F, Marzban H, Javanbakht J, Moosakhani F, Imanparast M (2013) The Relationship between Microscopic Lesions and Different Types of Clostridium perfringens and their Related Toxins by Sandwich ELISA in Cattle. J Microb Biochem Technol 5: 034-038. doi:10.4172/19485948.1000096

8. el Idrissi AH, Ward GE (1992) Development of double sandwich ELISA for Clostridium perfringens beta and epsilon toxins. Vet Microbiol 31: 89-99.

9. Ball HJ, Kerr S, Mackie DP (1993) Monoclonal antibody-based ELISAs New Techniques in Food, Beverage Microbiology, Society of Applied Bacteriology Technical Series no. 31 Blackwell Scientific Publications, Oxford 131-145.

10. Corrie CB, Dale CB, Ian KB (2007) Alimentary system. In: Jubb, Kennedy and Palmer's pathology of domestic animals, Maxie MG, (ed.). (5thedn), Elsevier Sanders, Philadelphia, USA 2: 1-296.

11. Mainil J, Duchesnes C, Granum PE, Menozzi MG, Peck M, et al. (2006) Clostridia in medical veterinary and food microbiology, Diagnosis and typing. European Concerted Action European 45-54

12. Manteca C, Daube G, Pirson V, Limbourg B, Kaeckenbeeck A, et al. (2001) Bacterial intestinal flora associated with enterotoxaemia in Belgian Blue calves. Vet Microbiol 81: 21-32.

13. Slavić D, Boerlin P, Fabri M, Klotins KC, Zoethout JK, et al. (2011) Antimicrobial susceptibility of Clostridium perfringens isolates of bovine, chicken, porcine, and turkey origin from Ontario. Can J Vet Res 75: 89-97.

14. Songer JG (1999) Clostridial enterotoxaemia (Clostridium perfringens). Vet Ther Food Anim Prac 19: 62.

15. Ghareib HHE, Amer HAM (2009) Pathological and bacteriological studies on Clostridium perfringens infection in kidney of cattle, camel and sheep. Egyp J Com Pathol Clinic Pathol 22: 88-108.

16. Filho EJ, Carvalho AU, Assis RA, Lobato FF, Rachid MA, et al. (2009) Clinicopathologic features of experimental Clostridium perfringens type $D$ enterotoxemia in cattle. Vet Pathol 46: 1213-1220.

17. Dennison AC, VanMetre DC, Callan RJ, Dinsmore P, Mason GL, et al. (2002)
Hemorrhagic bowel syndrome in dairy cattle: 22 cases (1997-2000). J Am Vet Med Assoc 221: 686-689.

18. Javed MT, Irfan M, Mukhtar N, Sajjad-Ur-Rahman, Hussain R (2009) An outbreak of enterotoxaemia at livestock farm during subtropical summer. Acta Trop 112: 225-227.

19. Lulov R, Angelov AK (1986) Enterotoxemia in newborn calves due to $\mathrm{Cl}$ perfringens types A, C and D. Vet Med Nauki 23: 20-28.

20. Glenn Songer J, Miskimins DW (2005) Clostridial abomasitis in calves: case report and review of the literature. Anaerobe 11: 290-294.

21. Tajik J, Mohammadi M, Rad M, Barati A (2010) Hemorrhagic bowel syndrome in dairy cattle in Iran: A case report. Iranian Journal of Veterinary Research 11: 180-183.

22. Watson PJ, Scholes SF (2009) Clostridium perfringens type D epsilon intoxication in one-day-old calves. Vet Rec 164: 816-817.

23. Fernandez-Miyakawa ME, Sayeed S, Fisher DJ, Poon R, Adams V, et al (2007) Development and application of an oral challenge mouse model for studying Clostridium perfringens type D infection. Infect Immun 75: 4282-4288.

24. Morris WE, Venzano AJ, Elizondo A, Vilte DA, Mercado EC, et al. (2011) Necrotic enteritis in young calves. J Vet Diagn Invest 23: 254-259.

25. Wang G, Zhou J, Zheng F, Lin G, Cao X, et al. (2010) Detection of Different Genotypes of Clostridium perfringens in Feces of Healthy Dairy Cattle from China using Real-Time Duplex PCR Assay. Pak Vet J 31: 120-124.

26. Hormitzky MAZ, Glastonbury J (1993) Enterotoxemia in sheep, goats and cattle. In: Australian standard diagnostic techniques for animal diseases, Corner LA, Bagust TJ, (ed.). Standing Committee on Agricultural and Resource Management, CSIRO, Melbourne, Australia 3-5. 